\title{
Air pollution and daily mortality in Rome, Italy
}

\author{
P Michelozzi, F Forastiere, D Fusco, C A Perucci, B Ostro, C Ancona, G Pallotti
}

Department of Epidemiology, Regional Health

Authority, Roma, Italy

P Michelozzi

F Forastiere

D Fusco

C A Perucci

C Ancona

\section{California}

Environmental

Protection Agency,

Berkeley, CA, USA

B Ostro

\section{Public Health}

Laboratory, Roma,

Italy

G Pallotti

Correspondence to:

Dr Francesco Forastiere,

Department of

Epidemiology, Lazio

Regional Health Authority,

Via Santa Costanza 53,

00198 Rome, Italy. Fax 0039

6 51686463; email

forastiere@compuserve.com

Accepted 16 April 1998

\begin{abstract}
Objectives- To assess the relation between several daily indicators of air pollution (particulates and gases) and daily mortality in the metropolitan area of Rome and in the central part of the city. Methods-Time series analysis. The associations between daily concentrations of pollutants (particles, $\mathrm{SO}_{2}, \mathrm{NO}_{2}, \mathrm{CO}, \mathrm{O}_{3}$ ) recorded by five fixed monitors and daily total mortality in the period from January 1992 to June 1995 were evaluated. The analysis included examination of the pollution effect on mortality by place of residence within the metropolitan area, by season, age, place of death (in and out a hospital), and cause of death (cardiovascular and respiratory disease). The Poisson model included loess smooth functions of the day of study, mean temperature, mean humidity, and indicator variables for day of the week and holidays.

Results-The mean daily number of deaths was 56.9 (44.8 among people $\geqslant 65$ years old). A mean of 36.3 deaths occurred in the city centre; 37.3 deaths a day were recorded in a hospital. Total mortality was significantly associated with a $10 \mu \mathrm{g} / \mathrm{m}^{3}$ increase in particles $(0.4 \%)$ on that day $(\log 0)$, and with a $10 \mu \mathrm{g} / \mathrm{m}^{3}$ increase in $\mathrm{NO}_{2}$ at lag $1(0.3 \%)$ and lag $2(0.4 \%)$ (1 and 2 days before, respectively). The effect of particles (lag 0 ) and of $\mathrm{NO}_{2}($ lag 2) on total mortality was higher among those living in the city centre $(0.7 \%$ and $0.5 \%$, respectively). The risk estimates were higher in
\end{abstract}

Table 1 Summary of environmental variables in Rome 1992-5

\begin{tabular}{|c|c|c|c|c|c|}
\hline \multirow[b]{2}{*}{ Variable } & \multirow[b]{2}{*}{ Mean ${ }^{\star}$} & \multirow[b]{2}{*}{$S D$} & \multicolumn{3}{|c|}{ Percentiles } \\
\hline & & & 25 & 50 & 75 \\
\hline Temperature $\left({ }^{\circ} \mathrm{C}\right)$ & 16.5 & 6.8 & 11.0 & 15.7 & 22.2 \\
\hline Humidity (\%) & 61.5 & 12.3 & 53.0 & 63.0 & 71.0 \\
\hline Particles $\left(\mu \mathrm{g} / \mathrm{m}^{3}\right)$ & 84.2 & 26.1 & 65.7 & 82.7 & 100.3 \\
\hline $\mathrm{SO}_{2}\left(\mu \mathrm{g} / \mathrm{m}^{3}\right)$ & 16.2 & 9.8 & 9.4 & 13.3 & 20.7 \\
\hline $\mathrm{NO}_{2}\left(\mu \mathrm{g} / \mathrm{m}^{3}\right)$ & 99.2 & 22.8 & 83.8 & 96.2 & 111.0 \\
\hline $\mathrm{CO}\left(\mathrm{mg} / \mathrm{m}^{3}\right)$ & 4.1 & 1.6 & 3.1 & 3.9 & 5.0 \\
\hline $\mathrm{O}_{3}\left(\mu \mathrm{g} / \mathrm{m}^{3}\right)$ & 25.9 & 19.6 & 10.3 & 21.0 & 36.0 \\
\hline
\end{tabular}

$\star 24 \mathrm{~h}$ mean for all except $\mathrm{O}_{3}$ which is $8 \mathrm{~h}$ mean.

Table 2 Summary of daily mortality data in Rome 1992-5

\begin{tabular}{|c|c|c|c|c|}
\hline \multirow[b]{2}{*}{ Variable } & \multicolumn{2}{|c|}{ Metropolitan area } & \multicolumn{2}{|c|}{ Central area } \\
\hline & Mean & $S D$ & Mean & $S D$ \\
\hline Whole year & 57.0 & 10.5 & 36.3 & 8.4 \\
\hline Cold period & 60.5 & 9.3 & 38.6 & 7.5 \\
\hline Warm period & 53.4 & 10.4 & 33.9 & 8.6 \\
\hline Among elderly people $(\geqslant 65)$ & 44.8 & 9.4 & 29.8 & 7.6 \\
\hline Deaths in hospital & 37.3 & 7.7 & 18.8 & 5.4 \\
\hline Deaths out of hospital & 19.4 & 5.3 & 17.5 & 5.3 \\
\hline Cardiovascular mortality & 23.3 & 6.4 & 15.3 & 5.1 \\
\hline Respiratory mortality & 3.2 & 2.0 & 2.1 & 1.6 \\
\hline
\end{tabular}

the warmer season $(1.0 \%$ and $1.1 \%$, respectively), whereas no difference was found for those dying in or out of the hospital. The effect of particles was robust to a sensitivity analysis and to the inclusion of $\mathrm{NO}_{2}$ in the regression model.

Conclusions-Increase in particulates and $\mathrm{NO}_{2}$, generated by the same mobile combustion sources, is associated with a short term increase in mortality in Rome. The effect is more evident among residents in the city centre, where the levels of exposure to pollutants recorded by fixed monitors are probably more reliable indicators of personal exposure.

(Occup Environ Med 1998;55:605-610)

Keywords: air pollution; time series; smoothing

Epidemiological studies conducted in the United States and Europe have provided evidence that serious health effects, including premature mortality, are associated with exposure to ambient particles found in urban environments, even at concentrations below current standards. ${ }^{1}$ Most studies evaluating the short term effects of pollutants on daily mortality have found a similar level of increase of risk per unit increase in particle concentration (total suspended particulates, or particulate matter with mean aerodynamic diameter of $\left.10 \mu \mathrm{m}\left(\mathrm{PM}_{10}\right)\right)$ across various geographical and climatic conditions. Ambient exposure to fine particles, $\mathrm{PM}_{2.5}$, may be primarily responsible for the association found ${ }^{2}$; yet the association between particle exposure and daily mortality has been questioned. ${ }^{3}$

The association between air pollution and daily mortality has been studied in Europe, mostly within the air pollution and health: a European approach (APHEA) initiative, ${ }^{45}$ a unique project aimed at evaluating the short term effect of pollution in 10 countries. In most European cities-for example, London ${ }^{6}$ and Birmingham $^{7}$ in the United Kingdom-an association between particulates and total mortality is clear. In the recent pooled analysis of 12 APHEA cities, both $\mathrm{SO}_{2}$ and particulate matter were found to be associated more or less equally with daily mortality. ${ }^{5}$

Few studies have been conducted within the Mediterranean area, and none in cities with low concentrations of $\mathrm{SO}_{2}$. In Rome, the main source of pollution is traffic that generates medium to high concentrations of airborne particles and $\mathrm{NO}_{2}$. By contrast with other western European areas where time series studies have been conducted, $\mathrm{SO}_{2}$ concentrations in Rome are low. We examined the association between daily concentration of various pollutants (particles, $\mathrm{SO}_{2}, \mathrm{NO}_{2}, \mathrm{CO}$, 
Table 3 Pearson correlation coefficients among daily environmental variables, Rome 1992-5

\begin{tabular}{lrrlrrrr}
\hline & Temperature & Humidity & Particles & \multicolumn{1}{c}{$\mathrm{SO}_{2}$} & $\mathrm{NO}_{2}$ & $\mathrm{CO}$ & $\mathrm{O}_{3}$ \\
\hline Temperature & 1.000 & & & & & & \\
Humidity & -0.300 & 1.000 & & & & & \\
Particles & 0.247 & -0.152 & 1.000 & & & & \\
$\mathrm{SO}_{2}$ & -0.621 & 0.132 & 0.267 & 1.000 & & & \\
$\mathrm{NO}_{2}$ & 0.058 & -0.100 & 0.507 & 0.409 & 1.000 & & \\
$\mathrm{CO}$ & -0.440 & 0.448 & 0.238 & 0.646 & 0.282 & 1.000 & \\
$\mathrm{O}_{3}$ & 0.604 & -0.437 & 0.223 & -0.263 & 0.237 & -0.479 & 1.000 \\
\hline
\end{tabular}
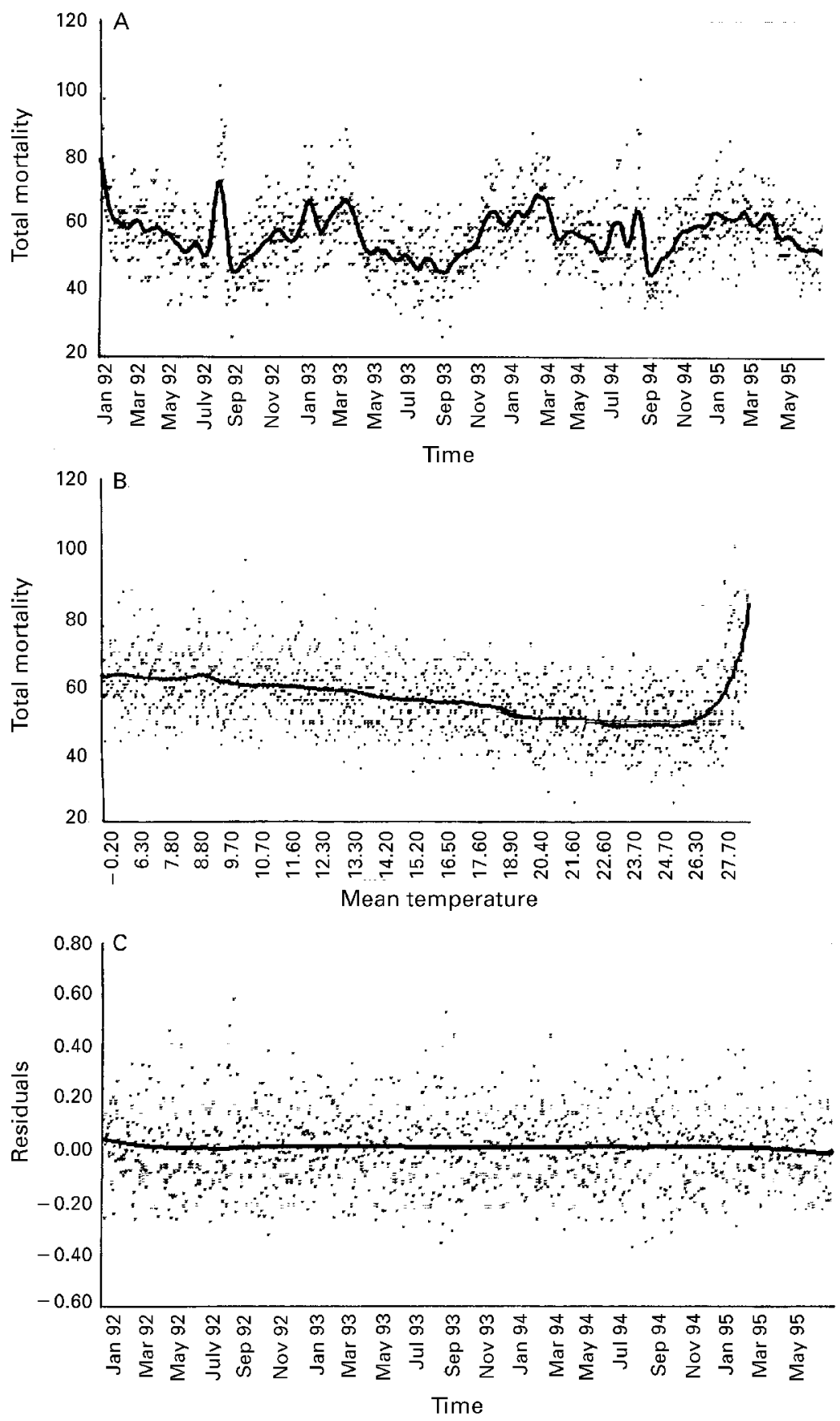

(A) Loess smoothing (span=0.03) of daily mortality in Rome. (B) Loess smoothing $\left(\right.$ span $=0.11$ ) of the relation between daily mean temperature $\left({ }^{\circ} \mathrm{C}\right)$ and daily mortality. (C) Loess smoothing (span=0.30) of the residuals from the basic Poisson model including smoothing of time, mean temperature (lag 1), relative humidity (lag 1), and indicators for day of the week and holidays.

$\mathrm{O}_{3}$ ) and daily total mortality in Rome in the period 1992-5. Detailed data were available on the specific area of residence within the metropolitan area, as well as on the place of death (hospital $v$ other dwellings) of the people who died during the study period. It was thus possible to evaluate whether the effects of pollution on mortality are actually higher among residents in the central city than among those living in the outskirts, and whether the effects are similar among people who die in a hospital and those who die at home.

\section{Methods}

AIR POLLUTION AND WEATHER DATA

The metropolitan area of Rome has a population of about three million inhabitants and covers an area of $1495 \mathrm{~km}^{2}$. About $65 \%$ of the population live in the city centre, which has been defined by the local authorities as the area of concern for air pollution control. The city centre (about $320 \mathrm{~km}^{2}$ ) includes archeological and historical sites, business areas, and residential neighbourhoods. A network of fixed air quality monitoring stations has been operating in Rome since January 1992 under the Regional Department of Environment. Five stations, located in densely populated areas within the central city, continuously collect hourly data on concentrations of $\mathrm{SO}_{2}$ (ultraviolet fluorescence), $\mathrm{NO}_{2}$ (chemiluminescence), and $\mathrm{CO}$ (infrared photometry); three of the five monitors also collect hourly data on $\mathrm{O}_{3}$ (ultraviolet photometry) and 2-hourly data on particles. Counts for $\mathrm{PM}_{10}$ were not available for the period under study. Suspended particles are continuously monitored with a low volume air sampler with an open face inlet and $\beta$ ray atomic absorption. Investigations in Rome with a gravimetric method to measure $\mathrm{PM}_{10}$ and total suspended particulates showed a higher ratio of $\mathrm{PM}_{10}$ to total suspended particulates $(0.70-0.80)$ than the ratios detected in North America. ${ }^{8}$ This is presumably due to both the low volume sampling and to the peculiar geometry of the open face inlet which produced a higher efficiency for small size particulate fractions. Furthermore, detailed examinations with electron microscopy of the relative size of the particles sampled with the Italian instrument indicated that the particle fraction actually measured is $<13 \mu \mathrm{m}$.

We collected the daily air pollution data (24hour integrated measure for particles, $\mathrm{SO}_{2}$, $\mathrm{NO}_{2}$, and $\mathrm{CO}$; the mean $\mathrm{O}_{3}$ concentration between 800 am and $400 \mathrm{pm}$ ) from the five population oriented fixed monitors. For each day, we averaged the data from the available monitors to compute a city mean to match the daily mortality data. During the study period (1 January 1992 to 30 June 1995) data were available from all the monitors for $72.3 \%$ of the days for particles, $91.5 \%$ for $\mathrm{SO}_{2}, 90.6 \%$ for $\mathrm{NO}_{2}, 99.8 \%$ for $\mathrm{CO}$, and $75.6 \%$ for $\mathrm{O}_{3}$. As some values for a particular monitor and a particular pollutant were missing, before computing city means we imputed missing data with regression models based on the other monitors' values; the estimated values were used only if the goodness of fit $\left(R^{2}\right)$ of the regression models was $>0.60$. After this procedure, the percentage of missing values was $2.6 \%$ for particles, $0.2 \%$ for $\mathrm{SO}_{2}, 0.2 \%$ for $\mathrm{NO}_{2}, 0.1 \%$ for 
Table 4 Increase (\%) in daily mortality for $10 \mu \mathrm{g} / \mathrm{m}^{3}$ increase in particles, $\mathrm{SO}_{2}, \mathrm{NO}_{2}, \mathrm{O}_{3}$, and for $1 \mathrm{mg} / \mathrm{m}^{3}$ increase in CO in the entire metropolitan area of Rome and in the central city (results from Poisson regression models, ${ }^{\star}$ Rome 1992-5)

\begin{tabular}{|c|c|c|c|c|c|}
\hline \multirow[b]{2}{*}{ Pollutant } & \multirow[b]{2}{*}{ Lags } & \multicolumn{2}{|c|}{ Metropolitan area } & \multicolumn{2}{|l|}{ Central area } \\
\hline & & Increase (\%) & $95 \% C I$ & Increase (\%) & $95 \% C I$ \\
\hline \multirow[t]{5}{*}{ Particles } & 0 & 0.38 & 0.09 to 0.68 & 0.66 & 0.31 to 1.02 \\
\hline & 1 & 0.26 & -0.03 to 0.56 & 0.45 & 0.10 to 0.81 \\
\hline & 2 & 0.07 & -0.20 to 0.34 & 0.23 & -0.12 to 0.58 \\
\hline & 3 & -0.02 & -0.29 to .25 & 0.07 & -0.28 to 0.42 \\
\hline & 4 & 0.08 & -0.19 to 0.36 & 0.13 & -0.22 to 0.48 \\
\hline \multirow{5}{*}{$\mathrm{SO}_{2}$} & 0 & -0.77 & -1.66 to 0.13 & -0.98 & -2.02 to 0.08 \\
\hline & 1 & -0.69 & -1.56 to 0.19 & -0.67 & -1.69 to 0.37 \\
\hline & 2 & -0.54 & -1.43 to 0.36 & -0.85 & -1.89 to 0.21 \\
\hline & 3 & -0.53 & -1.40 to 0.35 & -0.95 & -1.99 to 0.11 \\
\hline & 4 & -0.42 & -1.29 to 0.46 & -0.73 & -1.77 to 0.33 \\
\hline \multirow[t]{5}{*}{$\mathrm{NO}_{2}$} & 0 & 0.23 & -0.10 to 0.56 & 0.45 & 0.04 to 0.87 \\
\hline & 1 & 0.34 & 0.01 to 0.68 & 0.48 & 0.07 to 0.90 \\
\hline & 2 & 0.43 & 0.10 to 0.77 & 0.54 & 0.13 to 0.96 \\
\hline & 3 & 0.38 & 0.05 to 0.72 & 0.40 & -0.01 to 0.81 \\
\hline & 4 & 0.25 & -0.08 to 0.58 & 0.14 & -0.27 to 0.55 \\
\hline \multirow[t]{5}{*}{$\mathrm{CO}$} & 0 & 0.29 & -0.22 to 0.81 & 0.52 & -0.11 to 1.15 \\
\hline & 1 & 0.30 & -0.23 to 0.83 & 0.47 & -0.18 to 1.12 \\
\hline & 2 & 0.19 & -0.35 to 0.73 & 0.24 & -0.41 to 0.89 \\
\hline & 3 & 0.28 & -0.24 to 0.81 & 0.07 & -0.57 to 0.71 \\
\hline & 4 & 0.18 & -0.35 to 0.70 & 0.09 & -0.54 to 0.73 \\
\hline \multirow[t]{5}{*}{$\mathrm{O}_{3}$} & 0 & 0.07 & -0.34 to 0.48 & 0.21 & -0.28 to 0.70 \\
\hline & 1 & 0.38 & -0.03 to 0.79 & 0.45 & -0.06 to 0.96 \\
\hline & 2 & 0.28 & -0.13 to 0.69 & 0.36 & -0.13 to 0.85 \\
\hline & 3 & 0.29 & -0.12 to 0.70 & 0.32 & -0.17 to 0.81 \\
\hline & 4 & 0.28 & -0.13 to 0.69 & 0.33 & -0.16 to 0.82 \\
\hline
\end{tabular}

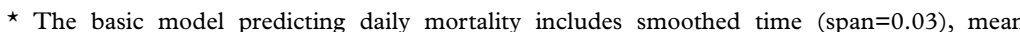
temperature (lag 1 ; span $=0.11$ ), and relative humidity (lag $1 ; \operatorname{span}=0.35$ ), indicators for days of the week and holidays. Each pollutant was entered as a continuous variable.

$\mathrm{CO}$, and $4.6 \%$ for $\mathrm{O}_{3}$. Mean daily temperature $\left({ }^{\circ} \mathrm{C}\right)$ and relative humidity (\%) were available from the local weather station in the central area.

DEATHS

We collected information on all deaths of residents in Rome during the study period, retrieved from the Regional Register of Deaths. Individual information on sex, age, census block of residence, date of death, municipality of death, place of death, and cause of death was available. Deaths due to accidents (international classification of diseases ninth revision (ICD-9 800-999)) and those occurring outside Rome were excluded from the analysis. The daily number of deaths was computed by place of residence within the metropolitan area (central area, outskirts) on the basis of the census block of residence, by age ( $<65$ years, $\geqslant 65$ years), place of death (inside or outside a hospital; dead on arrival at a hospital is usually coded as dead outside a hospital), and by cause (cardiovascular and respiratory disease).

\section{DATA ANALYSIS}

We used Poisson regression to estimate the association between pollutants at different lags and mortality in the entire metropolitan area and in the central area. The analysis was conducted in stages. Firstly, we developed the basic model to allow for time trends and weather variables (and possible serial correlation). Secondly, we tested the effect of the pollutants by adding continuous variables (with lags from 0 to 4 , on the same day to 4 days before) to the basic model. We then conducted a sensitivity analysis to evaluate the robustness of our findings to time trend and weather modelling. Finally, regressions in various subgroups were estimated and multipollutant models were evaluated.

To build the basic model, we used a Poisson regression replacing some of the covariates of a particular day with non-parametric smoothed data. $^{2910}$ The locally weighted (loess) smoothing technique ${ }^{11}$ can accommodate non-linear and non-monotonic patterns between the covariate and mortality, offering a flexible nonparametric tool. ${ }^{12}{ }^{13}$ We used loess smoothed data of time, mean temperature (at lag 1), and mean relative humidity (at lag 1 ). The choice of the appropriate span was based on the generalised cross validation criterion. ${ }^{14}$ To smooth daily total mortality against time, we chose to use $3 \%$ of the data (38 days), whereas $11 \%$ and $35 \%$ of the data were used to smooth temperature and humidity, respectively. We fitted separate smoothed data for each end point, although total, elderly, cardiovascular, and respiratory mortality showed similar patterns. The basic model also included indicator variables for day of the week and holidays.

For comparability with other studies, the results of our analysis were expressed as percentage increase in daily mortality with each increment of $10 \mu \mathrm{g} / \mathrm{m}^{3}$ in the pollutant (1 $\mathrm{mg} / \mathrm{m}^{3}$ for $\mathrm{CO}$ ). However, additional analysis was conducted with particles and $\mathrm{NO}_{2}$ divided into quartiles (indicator variables were considered) to evaluate the linearity of the effects as well as multipollutant models. Analysis was

Table 5 Increase (\%) in daily mortality for $10 \mu \mathrm{g} / \mathrm{m}^{3}$ increase in particles (lag 0) and in $\mathrm{NO}_{2}$ (lag 2) in the entire metropolitan area of Rome and in the central city, by season, age, place of death, and cause of death, Rome 1992-5

\begin{tabular}{|c|c|c|c|c|c|}
\hline \multirow[b]{2}{*}{ Variable } & \multirow[b]{2}{*}{ Pollutant } & \multicolumn{2}{|c|}{ Metropolitan area } & \multicolumn{2}{|l|}{ Central area } \\
\hline & & Increase (\%) & $95 \% C I$ & Increase (\%) & $95 \% C I$ \\
\hline \multirow[t]{2}{*}{ Whole year } & Particles & 0.38 & 0.09 to 0.68 & 0.66 & 0.30 to 1.02 \\
\hline & $\mathrm{NO}_{2}$ & 0.43 & 0.10 to 0.77 & 0.55 & 0.14 to 0.95 \\
\hline \multirow[t]{2}{*}{ Cold period } & Particles & 0.02 & -0.33 to 0.37 & 0.20 & -0.25 to 0.66 \\
\hline & $\mathrm{NO}_{2}$ & 0.07 & -0.32 to 0.46 & 0.32 & -0.19 to 0.83 \\
\hline \multirow{2}{*}{ Warm period } & Particles & 0.96 & 0.49 to 1.44 & 1.32 & 0.72 to 1.93 \\
\hline & $\mathrm{NO}_{2}$ & 1.10 & 0.48 to 1.71 & 0.97 & 0.21 to 1.73 \\
\hline \multirow[t]{2}{*}{ Among elderly peole $(\geqslant 65)$} & Particles & 0.42 & 0.11 to 0.74 & 0.74 & 0.34 to 1.13 \\
\hline & $\mathrm{NO}_{2}$ & 0.42 & 0.07 to 0.78 & 0.59 & 0.14 to 1.04 \\
\hline \multirow[t]{2}{*}{ Dead in hospital } & Particles & 0.40 & 0.05 to 0.76 & 0.58 & 0.09 to 1.08 \\
\hline & $\mathrm{NO}_{2}$ & 0.38 & -0.01 to 0.77 & 0.59 & 0.02 to 1.15 \\
\hline \multirow{2}{*}{ Dead out of hospital } & Particles & 0.37 & -0.12 to 0.86 & 0.69 & 0.18 to 1.21 \\
\hline & $\mathrm{NO}_{2}$ & 0.35 & -0.20 to 0.90 & 0.44 & -0.15 to 1.03 \\
\hline \multirow[t]{2}{*}{ Cardiovascular mortality } & Particles & 0.37 & -0.07 to 0.82 & 0.69 & 0.13 to 1.24 \\
\hline & $\mathrm{NO}_{2}$ & 0.39 & -0.11 to 0.89 & 0.54 & -0.08 to 1.15 \\
\hline \multirow[t]{2}{*}{ Respiratory mortality } & Particles & 0.29 & -0.90 to 1.47 & 0.34 & -1.12 to 1.80 \\
\hline & $\mathrm{NO}_{2}$ & -0.29 & -1.61 to 1.04 & -0.02 & -1.63 to 1.59 \\
\hline
\end{tabular}


Table 6 Increase (\%) in daily mortality for $10 \mu \mathrm{g} / \mathrm{m}^{3}$ increase and for quartiles of particles (lag 0) and $\mathrm{NO}_{2}$ (lag 2) in the entire metropolitan area of Rome and in the central city, in single, and two pollutant models, Rome 1992-5

\begin{tabular}{|c|c|c|c|c|c|}
\hline \multirow[b]{2}{*}{ Variable } & \multirow[b]{2}{*}{ Pollutant } & \multicolumn{2}{|c|}{ Metropolitan area } & \multicolumn{2}{|l|}{ Central area } \\
\hline & & Increase (\%) & $95 \% C I$ & Increase (\%) & $95 \% C I$ \\
\hline \multicolumn{6}{|l|}{ Single pollutant model: } \\
\hline Linear term $\left(10 \mu \mathrm{g} / \mathrm{m}^{3}\right)$ & Particles & 0.38 & 0.09 to 0.68 & 0.66 & 0.30 to 1.20 \\
\hline Quartiles & $\begin{array}{l}\mathrm{NO}_{2} \\
\text { Particles }\end{array}$ & 0.43 & 0.10 to 0.77 & 0.55 & 0.14 to 0.95 \\
\hline II & & 1.00 & -1.11 to 3.20 & 2.80 & 0.10 to 5.60 \\
\hline III & & 1.80 & -0.40 to 4.00 & 3.30 & 0.60 to 6.20 \\
\hline IV & & 3.80 & 1.70 to 5.90 & 5.80 & 3.10 to 8.60 \\
\hline Quartiles & $\mathrm{NO}_{2}$ & & & & \\
\hline II & & -1.80 & -3.90 to 4.70 & -0.20 & -2.80 to 2.50 \\
\hline III & & 2.50 & 0.30 to 4.70 & 5.00 & 2.30 to 7.90 \\
\hline IV & & 2.25 & 0.10 to 4.50 & 3.70 & 0.90 to 6.50 \\
\hline \multicolumn{6}{|l|}{ Two pollutant model: } \\
\hline Linear term $\left(10 \mu \mathrm{g} / \mathrm{m}^{3}\right)$ & Particles & 0.29 & -0.03 to 0.61 & 0.58 & 0.18 to 0.98 \\
\hline Quartiles & $\begin{array}{l}\mathrm{NO}_{2} \\
\text { Particles }\end{array}$ & 0.29 & -0.07 to 0.65 & 0.25 & -0.21 to 0.70 \\
\hline II & & 0.90 & -1.20 to 3.10 & 2.50 & -0.10 to 5.40 \\
\hline III & & 1.90 & -0.90 to 3.50 & 2.60 & -0.20 to 5.50 \\
\hline IV & & 3.10 & 0.90 to 5.30 & 4.70 & 1.90 to 7.70 \\
\hline Quartiles & $\mathrm{NO}_{2}$ & & & & \\
\hline II & & -2.20 & -4.24 to 0.00 & -0.74 & -3.30 to 2.00 \\
\hline III & & 1.80 & -0.40 to 4.00 & 4.00 & 1.20 to 6.90 \\
\hline IV & & 1.20 & -1.10 to 3.50 & 2.10 & -0.74 to 5.09 \\
\hline
\end{tabular}

conducted with STATA $^{15}$ and SAS. ${ }^{16}$ The S-Plus package ${ }^{17}$ was used to run robust Poisson regression to correct for overdispersion.

\section{Results}

Tables 1 and 2 summarise the environmental variables and daily mortality for the whole study period. Particles and $\mathrm{NO}_{2}$ did not follow a specific seasonal pattern. The $\mathrm{SO}_{2}$ and $\mathrm{CO}$ tended to be higher in winter than in summer, whereas $\mathrm{O}_{3}$ was higher in the warm season. There was a certain degree of collinearity among the environmental variables (table 3 ), especially between $\mathrm{SO}_{2}$ and $\mathrm{CO}(r=0.646)$, and between $\mathrm{NO}_{2}$ and particles $(r=0.507)$.

Rome had an average of 56.9 daily deaths during the 1277 days of the study. An average of 36.2 deaths occurred in the central area (tables 1 and 2). A strong seasonal pattern in mortality was evident (figure A), with excess deaths in winter. However, mortality peaked also in two of the three summers in the study period. There was a non-linear dependence of mortality on temperature (figure B), with a steep increase above $26^{\circ} \mathrm{C}$. After having considered all the time and weather variables, the distribution of the residual did not follow a particular pattern (figure C). Partial autocorrelation coefficients for the residuals of the basic model were inspected, and no residual autocorrelation was found up to seven days.

Table 4 shows the results from the Poisson regression analysis. Daily mortality in the metropolitan area was significantly associated with same day particle concentration $(0.38 \%$ increase per $10 \mu \mathrm{g} / \mathrm{m}^{3}$ ), and with $\mathrm{NO}_{2}$ at lag 1 , lag 2 , and lag 3 , with the highest effect at lag 2 $\left(0.43 \%\right.$ increase per $\left.10 \mu \mathrm{g} / \mathrm{m}^{3}\right)$. A borderline significant association was found for $\mathrm{O}_{3}$ at lag 1 , whereas no association was found for $\mathrm{CO}$ and $\mathrm{SO}_{2}$. When the analysis was restricted to the deaths occurring among residents of the central area, higher coefficients were found for particles $(0.66 \%$ at lag 0$)$ and for $\mathrm{NO}_{2}(0.55 \%$ at lag 2). No effect of $\mathrm{CO}, \mathrm{SO}_{2}$, or $\mathrm{O}_{3}$ was detected. The analysis of daily mortality only in the outskirts of Rome did not show a single significant association with pollution levels, and the coefficients for particles $(0.02 \%, 95 \%$ $\mathrm{CI}-0.47 \%$ to $0.51 \%)$ and $\mathrm{NO}_{2}(-0.21 \%, 95 \%$ CI -0.78 to 0.36 ) were significantly different from those estimated for the central area $(\mathrm{p}=0.04$ and $\mathrm{p}=0.04$, respectively).

The results for particles and $\mathrm{NO}_{2}$ were robust to changes in the modelling technique. The regression coefficients for the pollution effects were stable for a wide range of less stringent time spans (the same results were obtained up to a time span of 0.1). Small changes were found when indicator variables for hot and cold days (highest and lowest 10\% of the temperature distribution) were included in the model (particles $0.38 \%$ at lag $0,95 \% \mathrm{CI}$ 0.09 to $0.68 ; \mathrm{NO}_{2} 0.36 \%$ at lag $2,95 \%$ CI 0.03 to 0.70$)$. The $95 \%$ CI of the particles effect (0.08 to 0.69 ) and of the $\mathrm{NO}_{2}$ effect (0.09 to 0.78 ) changed only slightly when overdispersion was taken into account.

The results of the subgroup analysis are shown in table 5 . The association of particles and $\mathrm{NO}_{2}$ with total mortality in the metropolitan area was significantly stronger in the warmer season $(\mathrm{p}=0.04$ and $\mathrm{p}=0.02$, respectively). Slightly higher risk estimates for particles were consistently found among elderly people. There was no substantial difference in the effect for those dying in or out of a hospital. Cardiovascular mortality, but not respiratory mortality, was significantly associated with particles in the central area; however, the coefficients were not higher than those found for total mortality.

Considering the high degree of correlation between pollutants, especially between particles and $\mathrm{NO}_{2}$ it is difficult to determine the role of a single factor (table 6). However, when multipollutant models were run, the risk estimates decreased for both particles and $\mathrm{NO}_{2}$, but particles remained of borderline significance in the metropolitan area and significantly associated with mortality in the 
city centre. When concentrations of particles and $\mathrm{NO}_{2}$ were divided into quartiles, in single pollutant models, mortality increased by $3.8 \%$ (and by $5.8 \%$ in the central area) in the highest quartile of particles compared with the first quartile, and by $2.3 \%(3.7 \%$ in the central area) in the highest quartile of $\mathrm{NO}_{2}$. In the multipollutant model with quartiles of both particles and $\mathrm{NO}_{2}$, the effect of particles remained and an exposure-response relation was found. The results for $\mathrm{NO}_{2}$ were less consistent and not significant.

\section{Discussion}

We found that both particles and $\mathrm{NO}_{2}$ are associated with the daily count of deaths in Rome. The risk estimates were higher among citizens living in the city centre, as they probably more directly experienced the pollution levels recorded by the fixed monitors. No differences were found between those dying in the hospital and those at home. In the multipollutant models, the results for particles were more stable than those obtained for $\mathrm{NO}_{2}$. The body of evidence from the United States indicates an increase in daily mortality ranging from $0.5 \%-1.6 \%$ per $10 \mu \mathrm{g} / \mathrm{m}^{3}$ particle concentration. ${ }^{18}$ Studies conducted in western Europe have yielded slightly lower risk estimates of mortality associated with particle levels than those reported by United States time series analyses. ${ }^{5}{ }^{19-23}$ However, in most of the European cities that have been studied, other pollutants had a stronger effect on mortality. For example, $\mathrm{SO}_{2}$ was found to be associated with mortality in all cities with moderate to high concentrations of $\mathrm{SO}_{2}$ (Athens, ${ }^{19}$ Barcelona, ${ }^{20}$ Lyon $\left.^{21}\right)$. In London, $\mathrm{O}_{3}$ was a stronger determinant of mortality than black smoke. ${ }^{6}$

Our risk estimates of the effect of particles are similar to what has been found in the recent APHEA meta-analysis $(0.4 \%-0.5 \%$ increase per 10 unit increase). ${ }^{5}$ Our findings add weight to the general tendency of risk in Europe to be lower, and suggest that the detected effect varies according to the area investigated (from $0.38 \%$ in the entire metropolitan area to $0.66 \%$ when considering only the central area). There has been concern in the scientific literature over the use of fixed monitors in time series analysis, as they may not represent personal exposure. We interpret the stronger effect of particles found in the central area as an indication that refinement in the exposure assessment in time series may yield higher risk estimates. As all the pollution monitors in the metropolitan area of Rome are located within the central city, it is likely that they represent more the daily exposure to pollution of the citizens in the city centre than of those living in more suburban areas. Time series analyses in other European settings have usually considered the entire metropolitan area (although in some situations the distribution of fixed monitors is wider).

The effect of air pollution on mortality in Rome was clearly stronger in the warmer months. Other studies in Europe ${ }^{619-23}$ also have found an increased effect of air pollution in summer. There are three possible, nonmutually exclusive interpretations of the findings. Firstly, during the warmer period, other stronger determinants of daily mortality (such as acute respiratory infections) are less influential. Secondly, in the warmer period, people spend more time outdoors or tend to live with the windows left open so that exposure to air pollutants is higher and closer to what is being measured by the fixed monitors. Finally, temperature affects mortality through various mechanisms, ${ }^{24}$ and a biological interaction between air pollution and high temperature may exist, increasing the pollution effect, as has been shown for $\mathrm{SO}_{2}$ and high temperature in Athens. ${ }^{25}$

The biological mechanism underlying the association between exposure to particles and daily mortality and the population subgroups possibly more susceptible to the pollutant effects are still under debate. Our risk estimates due to particles were significant for cardiovascular disease, and the results are of interest because of the recent findings that relate particulate pollution to an increased plasma viscosity, ${ }^{26}$ and to electrocardiographic changes in a canine animal model. ${ }^{27}$ However, contrary to some studies, ${ }^{18}$ yet in agreement with others, ${ }^{6}$ we did not find a significantly increased risk for respiratory mortality, possibly as a result of insufficient power.

It has been proposed that the increase in particulate pollution precipitates deaths in already ill patients whose cardiorespiratory system is compromised. ${ }^{28}$ Following this assumption, people already in hospital should be a sensitive subgroup to the acute effects of air pollution, although in several instances air filtration or air conditioning reduces the exposure of hospital patients. In Rome, most hospitals do not have air filtration systems in the wards, and especially during summer, the air is changed through open windows. With the exception of hospital intensive care units, indoor and outdoor particle concentrations tend to be similar in the warm period. It is thus not surprising that we did not find a difference in the risk estimates between those dying in and out of a hospital. This comparison, however, has an unavoidable limitation in time series analysis, namely, the lack of information regarding the precise place at the time of the pollution increase. To date, this issue has not been systematically evaluated, although an increase in deaths outside hospital during high pollution days was noted in Philadelphia. ${ }^{28}$

Some studies have indicated short term effects of $\mathrm{NO}_{2}$ on hospital admissions and visits to emergency departments. ${ }^{29} 30$ Positive findings of $\mathrm{NO}_{2}$ on daily mortality have been reported from Los Angeles, ${ }^{31}$ and in the APHEA meta-analysis. ${ }^{4}$ However, from the studies available, the independent role of $\mathrm{NO}_{2}$ on mortality is difficult to separate from that of particles ${ }^{32}$ as often, as in Rome, both originate from the same sources, and $\mathrm{NO}_{2}$ may be a surrogate of the unmeasured concentration of fine particles. Moreover, as $\mathrm{NO}_{2}$ is converted to nitrates, it also contributes to the 
fine particle mass. We found the strongest association between $\mathrm{NO}_{2}$ and mortality at lag 2 , whereas the association with particles was maximum at lag 0 ; in the multipollutant models the effect of particles was more robust than that of $\mathrm{NO}_{2}$. These findings lead us to conclude that the association between $\mathrm{NO}_{2}$ and mortality may be mediated by a particulate effect.

Ozone is a pollutant of concern in the entire Mediterranean area, ${ }^{25}$ and an association with daily mortality has been reported in London. ${ }^{6}$ We found only slight evidence of an association with mortality in Rome: an increase in mortality of borderline significance was noted at lag 1 in both the metropolitan area and the city centre. However, our study may have been insufficiently sensitive to the $\mathrm{O}_{3}$ effects as a result of the position of the $\mathrm{O}_{3}$ monitors. It is known that $\mathrm{O}_{3}$ tends to be higher in the outskirts of cities, because of the scavenger effect of primary gases in the city centre, but the pollution monitors in Rome record only central city values.

In conclusion, the present study found an association between particulate pollution and daily total mortality in Rome. Unlike many cities in North America, where particulate pollution has many sources, mostly of industrial origin, pollution in Rome derives mostly from car traffic. Our findings emphasise the importance of considering transportation in cities as a public health issue. ${ }^{33}$

We thank Dr Ira Tager and Dr Nino Kunzli for their thoughtful comments. FF was partially supported by a short term fellowship from the Italian National Research Council (CNR).

1 US Environmental Protection Agency. Air quality criteria for particulate matter, Vol III of III. Washington, DC: EPA Office of Research and Development, 1996. (EPA/600/P95/001cF US.)

2 Schwartz J, Dockery DW, Neas LM. Is daily mortality associated specifically with fine particles? fournal of the Air and Waste Management Association, 1996;46:927-39.

3 Moolgavkar SH, Luebeck EG. A critical review of the evidence on particulate air pollution and mortality. Epidemiology 1996;7:420-8.

Touloumi G, Katsouyanni K, Zmirou D, et al. Short term effects of ambient oxidant exposure on mortality: a combined analysis within the APHEA project. Am F Epidemiol 1997;146: 177-85

5 Katsouyanni K, Touloumi G, Spix C, et al. Short term effects of ambient sulphur dioxide and particulate matter on mortality in 12 cities: results from time series data from the APHEA project. BMF 1997;314:1658-63.

6 Anderson HR, Ponce de Leon A, Bland JM, et al. Air pollu$1996 \cdot 312: 665-9$
7 Wordley Jo, Walters S, Ayres JG. Short term variations in hospital admissions and mortality and particulate air pollution. Occup Environ Med 1997;54:108-16.

8 Brook JR, Dann, TF, Burnett RT.The relationship among TSP, $\mathrm{PM}_{10}, \mathrm{PM}_{25}$, and inorganic constituents of atmospheric particulate matter at multiple Canadian locations. fournal of the Air and Waste Management Association 1997;47:2-19.

9 Schwartz J. Air pollution and hospital admissions for respiratory disease. Epidemiology 1996;7:20-8.

10 Schwartz J, Spix C, Touloumi G, et al. Methodological issues in studies of air pollution and daily counts of deaths or hospital admissions. I Epidemiol Community Health 1996;50 (suppl 1):S3-11.

11 Cleveland WS, Devlin SJ. Robust locally-weighted regression and smoothing scatterplots. Fournal of the American Statistical Association 1988;74:829-36.

12 Schwartz. Non-parametric smoothing in the analysis of air pollution and respiratory illness. Canadian fournal of Statistics 1994;22:471-87.

13 Hastie T, Tibshirani R. Generalized additive models. London: Chapman and Hall, 1990.

14 Efron B, Tibshirani R. An introduction to bootstrap. New York: Chapman and Hall, 1993.

15 StataCorp. Stata statistical software:release 5.0 College Station, TX: Stata Corporation, 1997.

16 SAS Institute. SAS/STAT, Version 6, 4th ed. Cary, NC: SAS Institute, 1989

17 StatSci. S-Plus. Seattle, Washington: StatSci, 1993.

18 Schwartz J. Air pollution and daily mortality: a review and meta analysis. Environ Res 1994;64:36-52.

19 Touloumi G, Pocock SJ, Katsouyanni K, et al. Short-term effects of air pollution on daily mortality in Athens: a timeseries analysis. Int 7 Epidemiol 1994;23:957-67.

20 Sunyer J, Castellsague J, Saez M, et al. Air pollution and mortality in Barcelona. $\mathcal{F}$ Epidemiol Community Health 1996;50 (suppl 1):S76-80.

21 Zmirou D, Barumandzadeh T, Balducci F, et al. Short term effects of air pollution on mortality in the city of Lyon, France, 1985-90. I Epidemiol Community Health 1996; 50(suppl 1):S30-5

22 Ballester F, Corella D, Perez-Hoyos S, et al. Air pollution and mortality in Valencia, Spain: a study using the APHEA methodology. F Epidemiol Community Health 1996;50:52733.

23 Verhoeff AP, Hoek G, Schwartz J, et al. Air pollution and daily mortality in Amsterdam. Epidemiology 1996;7:22530.

24 Khaw K-T. Temperature and cardiovascular mortality. Lancet 1995;345:337-8.

25 Katsouyanni K, Pantazopoulou A, Touloumi G, et al. Evidence for interaction between air pollution and high temperature in the causation of excess mortality. Arch temperature in the causation of

26 Peters A, Doring A, Wichmann H-E, et al. Increased plasma viscosity during an air pollution episode: a link to mortality. Lancet 1997;349:1582-7.

27 Godleski JJ, Sioutas C, Verrier RL, et al. Inhalation exposure of canines to concentrated ambient air particles. $A m \mathcal{F}$ Resp Crit Care Med 1997;155:A246.

28 Schwartz J. What are people dying of on high air pollution days? Environ Res 1994;64:26-35.

29 Castellsague J, Sunyer J, Saez M, et al. Short-term association between air pollution and emergency room visits for asthma in Barcelona. Thorax 1995;50:1051-6.

30 Pantazopoulou A, Katsouyanni K, Kourea-Kremastinou J, et al. Short-term effects of air pollution on hospital emergency out patient visits and admissions in the greate Athens, Greece area. Environ Res 1995;69:31-6.

31 Kinney Pl, Ozkaynak H. Associations of daily mortality and air pollution in Los Angeles County. Environ Res 1991;54: 99-120.

32 Anderson HR, Limb ES, Bland JM, et al. Health effects of an air pollution episode in London, December 1991. Tho$\operatorname{rax}$ 1995;50:1188-93.

33 Godlee F. Transport: a public health issue. BMF 1992;304 45-50. 